\title{
Reduced Levels of Total Leukocytes and Neutrophils in Norwegian Cattle Selected for Decreased Mastitis Incidence
}

\author{
S. Kulberg, ${ }^{\star}$ A. K. Storset, ${ }^{*}$ B. Heringstad, † and H. J. S. Larsen* \\ *Department of Pharmacology, Microbiology, and Food Hygiene, \\ The Norwegian School of Veterinary Science, \\ $\mathrm{N}-0033$ Oslo \\ †Department of Animal Science, \\ Agricultural University of Norway, \\ $\mathrm{N}-1432$ Ås
}

\section{ABSTRACT}

Two groups of Norwegian Cattle showing significant genetic differences in clinical mastitis susceptibility were examined for hematological changes at three stages of lactation. Blood samples were taken from 91 healthy Norwegian Cattle cows and heifers belonging either to a high protein yield group or to a low clinical mastitis group and analyzed for hematological properties and serum cortisol levels at three stages of lactation. All animals were free of intramammary infections at the time of sampling.

All cows had increased total white blood cells, neutrophils, and neutrophil/lymphocyte ratio as parturition approached, with peak levels at parturition. Cows selected for low clinical mastitis had lower levels of total white blood cells and neutrophils compared with cows selected for high protein yield throughout all three periods. The difference was significant prepartum. Cows from the low clinical mastitis group also had lower neutrophil/lymphocyte ratios and lower serum cortisol levels than those in the high protein yield group. A significant positive correlation was found between cortisol and total white blood cells and neutrophils, respectively.

We conclude that selection for lower mastitis incidence in the low clinical mastitis group is associated with a significant decrease in total white blood cells and neutrophils in blood prepartum. Results from the present study, and the genetic difference in mastitis incidence observed in the groups, indicates that increased leukocyte mobilization at certain stages of lactation may be associated with increased susceptibility to mastitis.

(Key Words: dairy cow, selected cattle group, parturition, leukocyte)

Abbreviation key: HPY = High protein yield, LCM = low clinical mastitis, N/L ratio = neutrophil/lymphocyte ratio, $\mathbf{N R F}=$ Norwegian Cattle.

Received October 9, 2001.

Accepted June 7, 2002

Corresponding author: Siri Kulberg; e-mail: siri.kulberg@veths.no.

\section{INTRODUCTION}

During the periparturient period, dairy cows are exposed to considerable hormonal changes and sudden onset of milk production, which impairs immune defense mechanisms (Kehrli et al., 1989; Mallard et al., 1998). Immunological dysfunctions have been observed from approximately $3 \mathrm{wk}$ prepartum until $3 \mathrm{wk}$ postpartum (Kehrli et al., 1989; Mallard et al., 1998; Kimura et al., 1999). Several in vitro experiments carried out in cattle during the same periparturient period have revealed decreased neutrophil function (Roth and Kaeberle, 1982; Detilleux et al., 1994; Kimura et al., 1999).

Despite the immunosuppression, increasing numbers of total white blood cells are found in the peripheral blood of periparturient animals, mainly due to a rise in neutrophil concentration. Peak values are observed at parturition, but levels decline shortly after and reach basal conditions within 2 wk postpartum (Detilleux et al., 1995; Kimura et al., 1999; Klinkon and Zadnik, 1999).

Neutrophils are crucial in protecting the body against invading pathogens. As a first group of defense they migrate rapidly into tissue where they phagocytose and kill invaders at sites of inflammation. Physiologically high periparturient blood concentrations of glucocorticoids have been suggested as an explanation for the increased neutrophil count around parturition (Burton et al., 1995; Lee and Kehrli, 1998; Kehrli et al., 1999).

Cortisol is a well-accepted indicator for stress in animals and man. A release of adrenocorticotropic hormone from the pituitary gland occurs in late pregnancy. Adrenocorticotropic hormones induce synthesis and secretion of glucocorticoids from the adrenal cortex. It is wellknown that glucocorticoids have an immunosuppressive effect (Kehrli et al., 1999). Although the exact mechanism is not completely understood, it is believed that glucocorticoids increase the bone marrow output of neutrophils and induces an enzymatic cleavage of L-selectin on the neutrophil surface. Reduced expression of L-selectin shifts the neutrophil population from the marginating pool to the peripheral circulation, and results in a larger 
circulating pool of neutrophils less capable of migrating towards sites of inflammation. Consequently animals become more susceptible to infections (Roth and Kaeberle, 1982; Burton et al., 1995; Lee and Kehrli, 1998).

The unfavorable genetic correlation between mastitis and milk yield (Heringstad et al., 2000), implies that single trait selection for increased milk production is expected to increase susceptibility to mastitis. In 1989, GENO Breeding and A. I. Association and Department of Animal Science, Agricultural University of Norway started a dairy cattle selection experiment that includes two selection groups of Norwegian Cattle (NRF); one high protein yield (HPY) group and one low clinical mastitis (LCM) group. More than 10 years of selection have resulted in two groups of cows with genetically different levels of susceptibility to clinical mastitis. The cows from this experiment represent a unique resource for studies of the underlying mechanisms causing a realized reduction in mastitis frequency among animals selected for improved health.

The aim of the present study was to observe the effect of different lactation stages on serum cortisol levels and hematological properties, especially neutrophil count, in the two groups of NRF selected for high protein yield or low clinical mastitis, respectively. We hypothesize that there might be differences in total white blood cells and neutrophil counts between the two groups.

\section{MATERIALS AND METHODS}

\section{Selection Experiment}

The two groups of cows (HPY and LCM) used in this study were from a Norwegian dairy cattle selection experiment. The experiment started in 1989 and included eight herds (seven agricultural schools and one state farm) in different parts of Norway. Each herd was divided in two groups with approximately the same number of cows in each group. The LCM and HPY group was established based on NRF cows selected for high milk yield from a previous selection experiment. Proven sires from the active breeding program of GENO Breeding and A. I. Associations were used as sires in the experiment. Each year, two to four of the highest-ranking sires with respect to EBV for protein yield or mastitis resistance, respectively, were selected among the 120 to 130 NRF test bulls that are progeny tested annually. This implies single trait selection of sires that were preselected for NRF breeding objective. NRF has been selected for a broad breeding objective, with increasing emphasize on functional traits like health and fertility over the last 20 years, and the current breeding objective results in genetic improvement for both protein yield and mastitis resistance (Heringstad et al., 2001).
Cows in the HPY group were mated to the two to four highest ranking proven sires with regard to protein yield each year, and cows in the LCM group were mated to the two to four best proven sires for mastitis resistance each year.

All cows present in the herd when the selection experiment started that were mated with one of the defined sires and produced a daughter that made a first lactation record of mastitis and/or protein yield were defined as cow-generation 0 , their daughters were defined as cow generation 1 , and so on. After three cow generations, the genetic difference between HPY and LCM cows was equivalent to $15.4 \mathrm{~kg}$ protein (305 d lactation yield, $\mathrm{kg}$ protein) and $8.6 \%$ clinical mastitis (B. Heringstad, 2002, unpublished). These estimated genetic differences were based on EBV for cows from linear animal model analysis of data for the total NRF population from 1978 to 1999. The mean EBV for the 34 sires used in the HPY group and the 28 sires used in the LCM group in the period from 1989 to 1998 was 0.0179 and -0.0727 for clinical mastitis and 24.36 and 2.83 for protein yield, respectively (B. Heringstad, 2002, unpublished).

\section{Animals and Blood Sampling}

Due to practical reasons, the four herds closest to the Norwegian School of Veterinary Science were chosen for this study (Buskerud, Jønsberg, Kalnes, and Mære). These herds do not differ from the other four herds except in location. Animals were chosen for sampling according to their expected calving dates, and the number of animals sampled in each herd according to the size of the herd. Animals, both primiparous and multiparous, with overlapping calving dates were chosen. An equal number of animals were sampled from each selection group.

Blood samples were taken from the jugular vein $2 \mathrm{wk}$ prior to calving, as soon as possible after calving, and 1 mo after calving. Milk samples were collected from all four quarters as soon as possible after calving and $1 \mathrm{mo}$ after calving. Because of the distances and the number of animals sampled, local veterinarians took most samples.

On each occasion, a $10 \mathrm{ml}$ sample of blood was withdrawn into Venoject glass tubes containing EDTA as anticoagulant (Terumo Europe N.V., Leuven, Belgium) for hematological analysis, while another $10 \mathrm{ml}$ sample was withdrawn into Venoject glass tubes with no anticoagulant (Terumo) to provide serum samples. The hematological analyses were performed shortly after sampling. The serum samples were stored frozen at $-20^{\circ} \mathrm{C}$ until analyzed.

Because several persons were involved in the sampling procedure, and predicting calving dates accurately is quite difficult, some of the samples were taken too late or too early in relation to the actual calving date or were 
Table 1. Total number of samples and individuals in the study, number of excluded samples, and total number of samples and individuals finally included from the low clinical mastitis (LCM) group and high protein yield (HPY) group.

\begin{tabular}{llllll}
\hline & \multicolumn{5}{c}{ Samples (individuals) } \\
\cline { 2 - 6 } & Total & LCM $^{1}$ & HPY & PP $^{3}$ & MP $^{4}$ \\
\hline Total number sampled & $311(121)$ & $179(68)$ & $132(53)$ & $89(39)$ & $222(84)$ \\
Excluded-outside sampling period & 85 & 48 & 43 & 27 & 58 \\
Excluded-mastitis & 57 & 33 & 18 & 15 & 42 \\
Total number of samples included & $169(91)$ & $98(54)$ & $71(37)$ & $42(27)$ & $122(66)$ \\
\hline${ }^{1} \mathrm{LCM}=$ Low clinical mastitis group. & & & & \\
${ }^{2} \mathrm{HPY}=$ High protein yield group. & & & & \\
${ }^{3} \mathrm{PP}=$ Primiparous. & & & & & \\
${ }^{4} \mathrm{MP}=$ Multiparous. & & & & & \\
\end{tabular}

not taken at all. In addition, some of the animals were culled during the sampling period. Finally, a total of 121 animals were sampled from the four herds (Table 1 ). 16 animals were sampled once, 26 animals were sampled twice, and 81 animals were sampled three times. There were no major differences in average age of the cows sampled, or in mean sampling day pre- or postpartum (Table 2).

The intervals studied were: (1) prepartum - not earlier than 28 and not later than $14 \mathrm{~d}$ prepartum; (2) parturition - within 5 d postpartum; and (3) peak lactation not earlier than 28 and not later than $60 \mathrm{~d}$ postpartum. All cows sampled outside these periods were excluded. Milk samples were cultured on blood agar plates using standard methodology (State Veterinary Laboratories of Norway, 1993) at the National Veterinary Institute, Oslo. The culturing was performed to identify individuals with pathogens indicative of clinical mastitis in their milk samples. If pathogens were detected in the cultured milk, the matching blood sample was discarded from the study.

A total of 85 cows were sampled outside the sampling periods and excluded (Table 1). There was no discrepancy between the groups. A total of 51 samples were excluded due to indications of udder infection (Table 1). The discrepancy seen between the groups were due to different numbers of animals sampled from each group. Additionally, some of the cows with indications of udder infection had a SCC within normal ranges, and it is questionable if these samples represent true udder infections. However, these samples were excluded the same way as samples with both pathogens in the milk and an increased SCC. In the LCM group, ten of these samples were found, compared with only four in the HPY group.

At the end, 91 cows were included in the study (Table 1 ), and more than $75 \%$ of these were from cow-generation 2 and $3 ; 4,7$, and 12 cows were from cow-generation 0 , 1 , and 4, respectively. The mean EBV for clinical mastitis for sires of the 53 LCM cows and sires of the $38 \mathrm{HPY}$ cows were -0.004 and -0.079 , respectively, a difference equivalent to $7.5 \%$ clinical mastitis. The corresponding mean EBV for protein yield (305 d lactation yield, $\mathrm{kg}$ protein) were 3.35 and 26.19 for sires of the LCM and HPY cows.

\section{Leukocyte Counting and Cortisol Analysis}

Haematological analyses were performed at the Central Laboratory, Norwegian School of Veterinary Science, Oslo. Total white blood cells $\left(\times 10^{6} / \mathrm{ml}\right)$ and differential counts $\left(\times 10^{6} / \mathrm{ml}\right)$ of monocytes, lymphocytes, neutrophils, eosinophils, and basophils, were calculated using a Technicon ADVIA 120 (Technicon Industrial Systems, Tarrytown, NY).

Serum cortisol levels were analyzed by radioimmunoassay (Simensen et al., 1978) at the Department of Re-

Table 2. Number of samples, average (SD) age of sampled animals, and average (SD) days pre-/postpartum each sample was collected for cows from the low clinical mastitis (LCM) group and high protein yield (HPY) group.

\begin{tabular}{|c|c|c|c|c|c|c|}
\hline & \multicolumn{2}{|c|}{ Prepartum } & \multicolumn{2}{|c|}{ Parturition } & \multicolumn{2}{|c|}{ Peak lactation } \\
\hline & LCM & HPY & LCM & HPY & LCM & HPY \\
\hline Number of samples & 33 & 18 & 31 & 25 & 34 & 28 \\
\hline Average age of animal ${ }^{1}$ & $38.9(12.5)$ & $40.83(15.3)$ & $41(14.7)$ & $41.5(16.6)$ & $40.8(12.1)$ & $38(14.7)$ \\
\hline Average sampling day & $-19.9(9.6)$ & $-20.3(4.2)$ & $2.3(1.7)$ & $2.1(1.5)$ & $36.9(5.7)$ & $39.1 \quad(7.9)$ \\
\hline
\end{tabular}

${ }^{1}$ age in months 


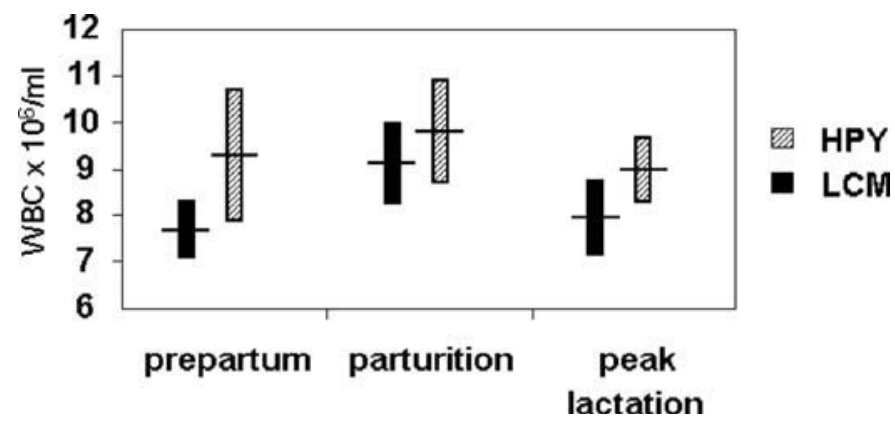

Figure 1. Mean (with 95\% confidence intervals) numbers of total white blood cells in peripheral blood of the high protein yield group (HPY) cows and the low clinical mastitis group (LCM) cows at three stages of lactation.

productive Physiology and Pathology, Norwegian School of Veterinary Science, Oslo.

\section{Statistical Analysis}

All results are expressed as mean values with $95 \%$ confidence intervals constructed using the Student procedure (Altmann, 1991). Standard deviation was used as the index for dispersion. Differences between groups were considered statistically significant if the $P$-value was less than or equal to a level of $5 \%$.

$P$-values were adjusted for multi-significance using the Bonferroni correction. An ANOVA expectation component model was used to compare groups, when variables could be assumed normally distributed (Altman, 1991).

Assumption of normality was rejected for neutrophils and cortisol. In these cases, the Wilcoxon two-sample test was used (Lehmann, 1975).

The Pearson linear correlation analysis was used to study the connection pattern between the included variables (Altman, 1991). All 169 single samples from the 91 animals included were used in the correlation analysis. The residual correlation for the four parameters, total white blood cells, neutrophils, the neutrophil/lymphocyte (N/L) ratio, and cortisol was calculated by correction for animal group and stage of lactation.

\section{RESULTS}

\section{Haematology}

In the time from the prepartum stage until parturition, significant increasing levels of total white blood cells (Figure 1) were seen in the LCM group, and significant increasing levels of neutrophils (Figure 2) were found in both groups. A rise in the N/L ratio (Figure 3) was also observed between the two stages. Peak values of all three parameters were found at parturition. The rise in total white blood cells was mainly due to increasing neutrophil numbers. A significant decline in total white blood cells was observed in the LCM group, and a significant decline in neutrophil levels was seen in both groups postpartum, reaching levels similar to those observed prepartum. The $\mathrm{N} / \mathrm{L}$ ratio also declined postpartum.

Leukocytosis was found at all stages of lactation in the HPY animals, neutrophilia only at parturition. Leukocytosis and neutrophilia were found at parturition in the LCM animals. Throughout all stages of lactation, the HPY cows showed higher concentrations of total white blood cells and neutrophils, and a higher N/L ratio than the LCM cows. The difference in total white blood cell concentration $(P \leq 0.02)$, neutrophil concentration $(P$ $\leq 0.002)$, and the $\mathrm{N} / \mathrm{L}$ ratio $(P \leq 0.01)$ was significant prepartum, but not at parturition nor at peak lactation.

As for the other leukocytes, monocyte and basophil levels increased during parturition, whereas lymphocyte and eosinophil levels decreased. There were no significant differences between the groups.

Significant, positive correlations were found between total white blood cells and neutrophils $(\mathrm{r}=0.81, P<$ $0.001)$, total white blood cells and N/L ratio $(\mathrm{r}=0.39, P$ $<0.001)$, and neutrophils and N/L ratio $(\mathrm{r}=0.78, P<$ 0.001). The results shown are correlations corrected for differences due to genetic group and stage of lactation.

\section{Cortisol}

Serum cortisol levels (Figure 4) increased as parturition approached, with peak levels at parturition. Slightly decreasing levels were found postpartum. Throughout all three periods, serum cortisol levels were higher in the HPY group than in the LCM group, although not significantly.

Significant positive correlations were found between total white blood cells and cortisol $(\mathrm{r}=0.24, P<0.01)$, and neutrophils and cortisol $(\mathrm{r}=0.29, P<0.001)$. The

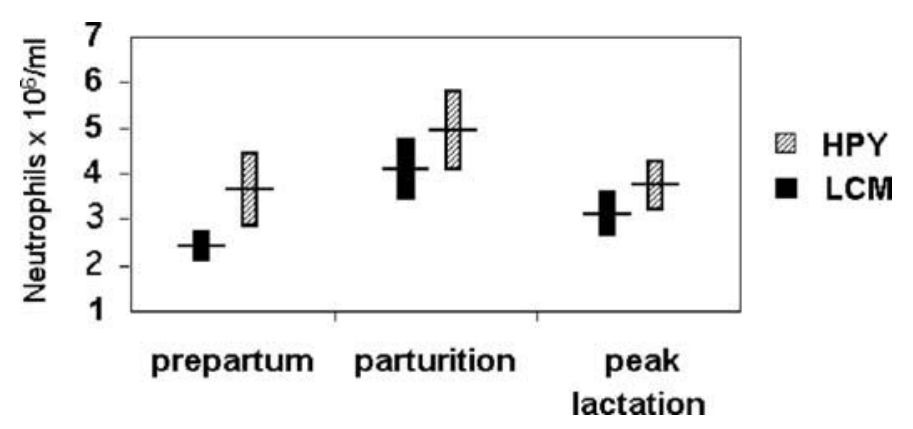

Figure 2. Mean (with 95\% confidence intervals) numbers of neutrophils in peripheral blood of the high protein yield group (HPY) cows and the low clinical mastitis group (LCM) cows at three stages of lactation. 


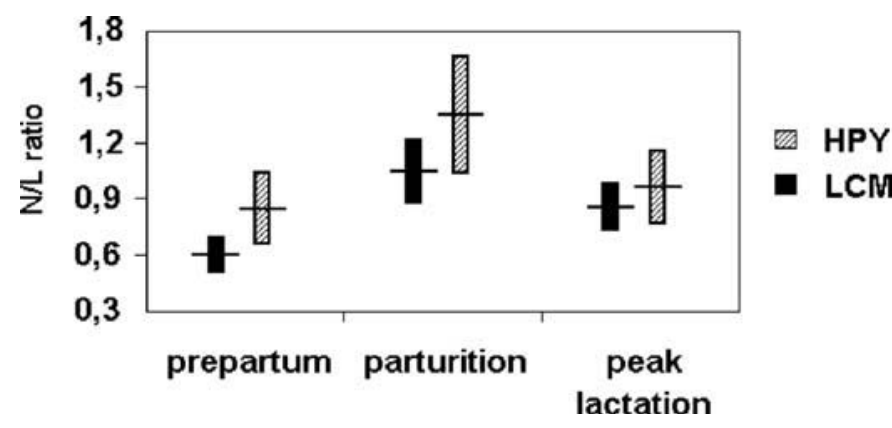

Figure 3. Mean (with 95\% confidence intervals) neutrophil/lymphocyte ratio (N/L ratio) in peripheral blood of the high protein yield group (HPY) cows and the low clinical mastitis group (LCM) cows at three stages of lactation.

results are correlations corrected for differences due to genetic group and stage of lactation.

\section{DISCUSSION}

In the present study, increasing numbers of total white blood cells and neutrophils were observed in the peripheral blood of periparturient cows prior to parturition. The total white blood cell rise was mainly caused by an increase in the number of neutrophils. These results are consistent with findings in periparturient cattle described by other authors (Detilleux et al., 1994; Kimura et al., 1999; Klinkon and Zadnik, 1999). The present study detected higher blood neutrophil concentrations in HPY animals compared to LCM animals during all stages of lactation investigated. However, the difference was only significant prepartum. In a study on Holstein cows selected for high or average milk production, significantly higher numbers of neutrophils were found in the peripheral circulation of high milk producers than in average milk producers during the periparturient period (Detilleux et al., 1995). Our study observed higher neu-

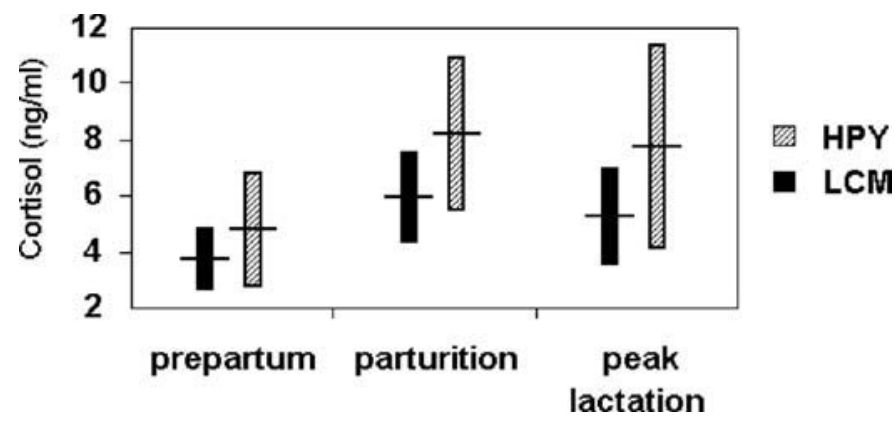

Figure 4. Mean (with 95\% confidence intervals) serum cortisol levels in peripheral blood of the high protein yield group (HPY) cows and the low clinical mastitis group (LCM) cows at three stages of lactation. trophil numbers in HPY cows, which show differences in genetic level for protein yield compared with LCM cows.

The N/L ratio in both selection groups increased as parturition approached. In the HPY group, the N/L ratio was higher than in the LCM group on all sampling occasions. The difference was significant prepartum. An increased N/L ratio has been described previously in animals under conditions of stress (McGlone et al., 1993; Stull and Rodiek, 2000).

Serum cortisol levels were higher in the HPY group than the LCM group at all stages of lactation. Levels increased up to parturition, where they reached their peak. After parturition, the cortisol concentration slowly decreased.

Experimental injections with synthetic glucocorticoids to create artificial stress similar to the stress seen in the periparturient period induced marked neutrophilia and down-regulation of L-selectin on neutrophil membranes. The neutrophils became less able to migrate and the susceptibility to infections increased (Burton et al., 1995; Nakagawa et al., 1999). The present study detected a significant positive correlation between neutrophils and the plasma cortisol level in the two groups.

The periparturient period induces physiological stress in cattle. It has been shown that transport-induced stress in different species leads to elevated cortisol blood concentrations, increases in total white blood cell and neutrophil levels, and an elevated N/L ratio (Dalin et al., 1993; McGlone et al., 1993; Stull and Rodiek, 2000). Animals highly susceptible to stress would almost certainly produce higher levels of cortisol in the periparturient period than less susceptible individuals, and would as a result have higher total white blood cells and neutrophil concentrations in blood than the less susceptible animals.

Different basal cortisol levels in blood have been observed among breeds with different susceptibility to stress (Zavy et al., 1992; Garcia-Belenguer et al., 1996), suggesting a genetic effect of this parameter. This results in permanently higher physiological total white blood cell and neutrophil numbers. On the other hand, cattle selected for fighting and dominance ability, although having the same basal cortisol levels as other breeds, were less fearful to surprising- effect tests, and experienced a less pronounced rise in cortisol levels, than other breeds, when subjected to stress (Plusquellec and Bouissou, 2001).

Whether the rise in cortisol level is permanently present, or only under temporary conditions of stress, it nevertheless may result in neutrophils being less capable of migration and phagocytosis, and consequently in animals with higher susceptibility to infectious diseases.

In the present study, increases in total white blood cells, neutrophils and the N/L ratio were significantly 
higher in the HPY group than in the LCM group prepartum.

Hematological changes prepartum are stress related, previously connected with the periparturient period. It is not possible to conclude solely based on this investigation whether the changes observed prepartum are permanent or if they are induced by the periparturient period. However, it is reasonable to suggest that the changes observed are either due to periparturient stress, and that the HPY group may be more affected by this than the LCM group, or that the differences may be permanent and due to higher basal cortisol levels in the HPY group. A difference in leukocyte recruitment between the groups is also a possibility and may represent a stronger inflammatory response upon local stimulation in the HPY group.

\section{CONCLUSION}

The LCM group of NRF showed significantly lower total white blood cell and neutrophil levels in blood prepartum than the HPY group. The difference was also present at parturition and at peak lactation, but not to a significant degree. It is reasonable to postulate that the difference is genetically predisposed, possibly caused by higher stress susceptibility, or higher leukocyte recruitment due to stronger inflammatory responses in the HPY group. This may partly explain the difference in mastitis susceptibility between these groups.

Further studies are needed to draw a firm conclusion. Analysis of neutrophil counts and baseline cortisol levels in the groups at other stages of lactation, will also reveal possible differences here, or support the hypothesis that the differences are related to the periods investigated in this study.

\section{ACKNOWLEDGMENTS}

The authors would like to thank the herd employees at the agricultural schools: Buskerud, Jønsberg, Kalnes, and Mære for assistance with animal handling and blood sampling, Stig Larsen for statistical assistance, Ståle Sviland for the culturing of milk samples, and Ellen Dahl for assistance with cortisol analysis.

\section{REFERENCES}

Altman, D.G. 1991. Practical statistics for medical research, 1st ed. Chapman and Hall, CRC, London.

Burton, J. L., M. E. Kehrli, S. Kapil, and R. L. Horst. 1995. Regulation of L-selectin and CD18 on bovine neutrophils by glucocorticoids: effects of cortisol and dexamethason. J. Leukoc. Biol. 57:317-325.
Dalin, A. M., U. Magnusson, J. Haggendal, and L. Nyberg. 1993. The effect of transport stress on plasma levels of catecholamines, cortisol, corticosteroid-binding globulin, blood cell count, and lymphocyte proliferation in pigs. Acta Vet. Scand. 34:59-68.

Detilleux, J. C., M. E. Kehrli, J. R. Stabel, A. E. Freeman, and D. H. Kelley. 1995. Study of immunological dysfunction in periparturient Holstein cattle selected for high and average milk production. Vet. Immunol. Immunopathol. 44:251-267.

Detilleux, J. C., K. J. Koehler, A. J. Freeman, M. E. Kehrli, and D. H. Kelley. 1994. Immunological parameters of periparturient holstein cattle: genetic variation. J. Dairy Sci. 77:2640-2650.

Garcia-Belenguer, S., J. Palacio, M. Gascon, C. Acena, R. Revilla, and P. Mormede. 1996. Differences in the biological stress responses of two cattle breeds to walking up to mountain pastures in the Pyrenees. Vet. Res. 27:515-526.

Heringstad, B., G. Klemetsdal, and J. Ruane. 2000. Selection for mastitis resistance in dairy cattle: a review with focus on the situation in the Nordic countries. Livst. Prod. Sci. 64:95-106.

Heringstad, B., G. Klemetsdal, and J. Ruane. 2001. Responses to selection against clinical mastitis in the Norwegian Cattle population. Acta Agric. Scand., Sect. A. Animal Sci. 51:155-160.

Kehrli, M. E., J. L. Burton, B. J. Nonnecke, and E. K. Lee. 1999. Effects of stress on leukocyte trafficking and immune responses: implications for vaccination. Adv. Vet. Med. 41:61-81.

Kehrli, M. E., B. J. Nonnecke, and J. A. Roth. 1989. Alterations in bovine neutrophil function during the periparturient period. Am. J. Vet. Res. 50:207-214.

Kimura, K., J. P. Goff, and M. E. Kehrli. 1999. Effects of the presence of the mammary gland on expression of neutrophil adhesion molecules and myeloperoxidase activity in periparturient dairy cows. J. Dairy Sci. 82:2385-2392.

Klinkon, M., and T. Zadnik. 1999. Dynamics of red and white blood picture in dairy cows during the periparturient period. Comparative Haematology International 9:156-161.

Lehmann, E. L., and H. J. M. D'Abrera. 1975. Nonparametrics: statistical methods based on ranks, 1st ed. Holden-Day, San Francisco.

Lee, E., and M. E. Kehrli. 1998. Expression of adhesion molecules on neutrophils of periparturient cows and neonatal calves. Am. J. Vet. Res. 59:37-43.

Mallard, B. A., J. C. Dekkers, M. J. Ireland, K. E. Leslie, S. Sharif, C. L. Vankampen, L. Wagter, and B. N. Wilkie. 1998. Alteration in immune responsiveness during the peripartum period and its ramification on dairy cow and calf health. J. Dairy Sci. 81:585-595.

McGlone, J. J., J. L. Salak, E. A. Lumpkin, R. I. Nicholson, M. Gibson, and R. L. Norman. 1993. Shipping stress and social status effects on pig performance, plasma cortisol, natural killer cell activity, and leukocyte numbers. J. Anim. Sci. 71:888-896.

Nakagawa, M., G. P. Bondy, D. Waisman, D. Minshall, J. C. Hogg, and S. F. van Eeden. 1999. The effect of glucocorticoids on the expression of L-selectin on polymorphonuclear leukocytes. Blood 93:2730-2737.

Plusquellec, P., and M. Bouissou. 2001. Behavioural characteristics of two dairy breeds of cows selected (Herens) or not (Brune des Alpes) for fighting and dominance ability. Appl. Anim. Behav. Sci. 72:1-21.

Roth, J. A., and M. L. Kaeberle. 1982. Effect of glucocorticoids on the bovine immune system. J. Am. Vet. Med. Assoc. 180:894-901.

Simensen, E., L. D. Olson, W. J. Vanjonack, H. D. Johnson, and M. P. Ryan. 1978. Determination of corticosterone concentration in plasma of turkeys using radioimmunoassay. Poult. Sci. 57:17011704.

State Veterinary Laboratories of Norway. 1993. Routines for mastitis diagnostics. State Vet. Lab., Oslo, Norway.

Stull, C. L., and A. V. Rodiek. 2000. Physiological responses of horses to 24 hours of transportation using a commercial van during summer conditions. J. Anim. Sci. 78:1458-1466.

Zavy, M. T., P. E. Juniewicz, W. A. Phillips, and D. L. VonTungeln. 1992. Effect of initial restraint, weaning, and transport stress on baseline and ACTH-stimulated cortisol responses in beef calves of different genotypes. Am. J. Vet. Res. 53:551-557. 